\title{
Effect of routine controlled cord traction as part of the active management of the third stage of labour on postpartum haemorrhage: multicentre randomised controlled trial (TRACOR)
}

In this Research paper by Catherine Deneux-Tharaux and colleagues (BMJ 2013;346:f1541, doi:10.1136/bmj.f1541), the full address for François Goffinet should have included the university's name: Port-Royal Maternity Unit, Department of Obstetrics and Gynaecology, Cochin University Hospital,
Assistance Publique Hôpitaux de Paris, Paris Descartes University, Paris.

Cite this as: BMJ 2013;346:f2542

๑ BMJ Publishing Group Ltd 2013 